\title{
Secondary Reconstruction of Frontal Sinus Fracture
}

\author{
Yang Woo Kim, \\ Dong Hun Lee, \\ Young Woo Cheon \\ Department of Plastic and Reconstructive \\ Surgery, Gachon University Gil Medical \\ Center, Incheon, Korea
}

No potential conflict of interest relevant to this article was reported.

\begin{abstract}
Fractures of frontal sinus account for $5 \%-12 \%$ of all fractures of facial skeleton. Inadequately treated frontal sinus injuries may result in malposition of sinus structures, as well as subsequent distortion of the overlying soft tissue. Such inappropriate treatment can result in aesthetic complaints (contour deformity) as well as medical complications (recurrent sinusitis, mucocele or mucopyocele, osteomyelitis of the frontal bone, meningitis, encephalitis, brain abscess or thrombosis of the cavernous sinus) with potentially fatal outcomes. Frontal contour deformity warrants surgical intervention. Although deformities should be corrected by the deficiency in tissue type, skin and soft tissue correction is considered better choice than bone surgery because of minimal invasiveness. Development of infection in the postoperative period requires all secondary operations to be delayed, pending the resolution of infectious symptoms. The anterior cranial fossa must be isolated from the nasal cavity to prevent infectious complications. Because most of the complications are related to infection, frontal sinus fractures require extensive surgical debridement and adequate restructuring of the anatomy. The authors suggest surgeons to be familiar with various methods of treatment available in the prevention and management of complications following frontal sinus fractures, which is helpful in making the proper decision for secondary frontal sinus fracture surgery.
\end{abstract}

Keywords: Frontal sinus fracture / Secondary reconstruction / Reoperation

\section{INTRODUCTION}

Fractures involving frontal sinus account for $5 \%$ to $12 \%$ of all fractures of facial skeleton [1-6]. The frontal sinuses are pockets of space located above the orbit of each eye within the frontal bone. They are lined with mucous membrane, which secretes fluid that moistens and protects the nasal lining. The mucus drains through the infundibulum of the nasofronatal duct into the hiatus semilunaris and rest of the nasal cavity. The surgeon should be always aware of the obstruction of drainage system because this could make many complications. Due to the anatomic position of the frontal sinus and enormous amount of force required to create a

Correspondence: Young Woo Cheon

Department of Plastic and Reconstructive Surgery, Gachon University Gil Medical Center, Gachon University College of Medicine, 21 Namdong-daero 774 beon-gil, Namdong-gu, Incheon 21565, Korea

E-mail: youngwooc@gmail.com

Received April 3, 2016 / Revised May 24, 2016 / Accepted May 24, 2016 fracture in this area, frontal bone fractures can be accompanied by concomitant injuries to the skull base, intracranial tissue, the orbital bones, and other facial bones.

Inadequately treated frontal sinus fractures may result in malposition of fractured segments as well as subsequent distortion of the overlying soft tissue. Such anatomical disruptions could result in contour deformity and also cause recurrent sinusitis, mucocele or mucopyocele, osteomyelitis of the frontal bone, meningitis, encephalitis, brain abscess or thrombosis of the cavernous sinus.

Proper management of frontal sinus fractures is all the more essential because of its proximity to vital structures, the brain. Despite this, the management of frontal sinus fractures remains controversial because postoperative complications can occur years to decades after the intervention. The consensus on posttraumatic frontal sinus reconstruction is that immediate treatment affords the best opportunity to restore the facial aesthetics, maintain the sinus function, and prevent many possible long- 
term risks of complications. Management options for frontal sinus fracture ranges from non-surgical treatment to open reduction and internal fixation with sinus conservation, and obliteration or cranialization of frontal sinus. In any given patient, the treatment modality should be based on the degree of fracture displacement, status of frontal sinus outflow tract, associated intracranial injuries. Depending on the institutional context, the patient may be cared by surgeons from a handful of specialties, such as otorhinolaryngologists, neurosurgeons, plastic or maxillafacial surgeons.

In this paper, we review the up-to-date literature regarding secondary reconstruction of frontal sinus fractures and assess the proper reconstructive options according to the cause of complications.

\section{CLASSIFICATION OF FRONTAL SINUS FRACTURES}

The primary treatment goal of facial injuries is to preserve both form and function. Therefore, treatment goals of the frontal sinus fracture are to maintaining sinus function, restoration of facial aesthetics, and prevention of complications.

Numerous classification schemes have been proposed of frontal sinus fracture [1,5,7-11]. Of all studies, a classification based on the involvement of frontal sinus outflow tract would best help to determine the treatment of frontal sinus fracture, from conservative treatment to operation [5]. However, the injury to the sinus outflow tract is not always easily detected on computed tomography (CT) scan, and the leakage of cerebrospinal fluid could be a cornerstone to determining treatment options [10]. Two major factors in considering treatment algorithm are patency of the frontonasal duct and persistence of the cerebrospinal fluid leaks. If the frontonasal duct is compromised, sinus obliteration or cranialization is required to prevent mucocele formation and infection.

\section{Clinical features of frontal sinus fractures}

Frontal sinus fractures are difficult to diagnose without radiologic studies, because the soft-tissue edema often obscures physical examination of the frontal bone. Signs suggestive of frontal sinus fracture include hypoesthesia of forehead and scalp, cerebrospinal rhinorrhea, subconjunctival ecchymosis, air in the orbit, depression over the forehead, or fractured bony fragments visible through an open wound [12].

All patients with severe head injury require high-resolution CT study for identification of intracranial injuries, which is more than adequate in assessing the frontal sinus. The presence of pneumocranium indicates posterior frontal sinus wall and/or skull base fracture, which is associated with significant intracranial hemorrhage in most cases (Fig. 1). This initial set of CT images are helpful not only in assessing the fracture itself but can also assist in medical decision making process and allows for comparisons to the postoperative CT scan. In addition, preoperative CT scans are helpful in identifying any injuries to frontonasal ducts [13].

The optimal method of treatment is determined by the site and extent of frontal sinus fracture. Accompanying facial bone fractures or brain injury could influence the treatment method as well as operation timing.

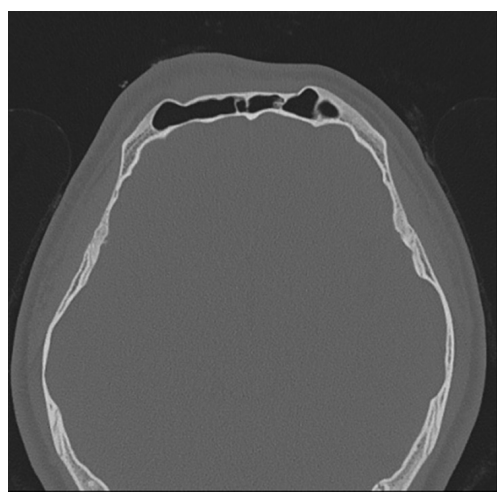

Fig. 1. Fracture of right frontal sinus anterior table.

Table 1. Complications after frontal sinus fracture treatment Complications after frontal sinus fracture treatment

I. Aesthetic problems (Irregular contour)

1. Bony framework

2. Skin and soft tissue

II. Infectious problem

1. Sinusitis

2. Mucocele and mucopyocele

3. Osteomyelitis of frontal bone

4. Pott's puffy tumor

5. Other infectious problem 


\section{COMPLICATION AFTER FRONTAL SINUS FRACTURE TREATMENT}

Complications after frontal sinus fracture treatment were subdived into aesthetic problems and infectious problem (Table 1).

\section{SECONDARY TREATMENT OF COMPLICATIONS AFTER FRONTAL SINUS FRACTURE}

\section{Aesthetic problems}

The frontal sinus fractures are typically the result of high-energy injuries with a force between 800 and 1,600 ft-lb. In addition to causing the fracture, the force can also damage the soft tissue and result in subsequent soft-tissue atrophy. The combination between fracture and soft-tissue atrophy explains the spectrum of aesthetic complications of frontal sinus fracture $[14,15]$. In terms of contour, patients complain of forehead contour irregularity with protuberance or depression that causes washboard effect in the overlying soft tissue. Such deformities can occur for one or more of the following reasons: (1) failure to recognize that a displaced fragment will result in bony depression once the overlying soft tissue edema resolves; (2) inadequate realignment of displaced fragments; (3) overlying soft tissue atrophy by high energy injury; (4) elevation of a galeal flap that was used to address intracranial or cranial base injury; and (5) palpable metal plates and screws that were used for fixation of reduced frontal bone. It is important to note that contour deformity represents the most common cause of surgical "second look".

Bony framework is mainly affected by the adequacy of reduction. Kim et al. reported that contour deformity was rarely an issue for fractures whose posterior displacement was at or less than $4 \mathrm{~mm}$. However, overlapped fractured edges may become palpable and become a source of postoperative complaint [16]. Forehead contour deformities can be managed by open reduction of displaced fracture, autologous bone graft from calvarium or pelvic bone, or onlay graft of alloplastic material. Irregularities based on mal-unioned bony base will require alloplastic or autogenous material or a combination of the two. Hydroxyapatite cement is useful when the deformity is scattered and depressed with concavity [17]. Also, Chen et al. [18] reported satisfactory outcomes following correction of frontal contour irregularities using hydroxyapatite cement and noted that the use of biocompatible alloplastic material was associated with stable volume maintenance. In fact, much of the recent literature on this topic seems to favor the use of alloplastic materials, such as hydroxyapatite and carbonated apatite, over the use of autologous bone graft for anterior table reconstruction [17-22].

In addition to bony depressions, patients may suffer from scars or dimples over the forehead. Such changes to skin texture may develop as a result of laceration, abrasion, surgical incision, or from adhesions between skin-soft tissue envelope and underlying structures. Depressions limited to soft tissue could be treated by filler injection or fat grafting [23]. Fat grafting has many advantages over filler injection because it is autologous and semipermanent. Moderate scarring of soft tissue could be treated fat graft with V-dissector that could release scar contracture. Fat graft alone may not be adequate in addressing soft-tissue problems arising from severe scarring of soft tissue. Dermofat graft could be an alternative to release severe depression with scarring. It is especially useful when previous operative skin scar was noted. However, if there were no previous scar near the depression site, the use of dermofat is limited because surgeon should made new incision to inset the dermofat (Figs. 2, 3).

\section{Infectious problem}

Posttraumatic and postoperative infections are more common for patients with multiple fractures or complex fractures than for patients with simple isolated fractures. The highest incidence is found with open fractures from penetrating trauma. Also, the risk of infection is higher for those fractures with concomitant maxillofacial injuries, possibly due to greater bone and mucosal destruction [24-26].

In physiologic state, the ciliated sinus epithelium transports the secreted mucus through the nasofrontal duct into the nasal cavity. Preserving this drainage system has been the main goal in the management of frontal sinus fractures. Treatment options include observation, endoscopic drainage, open reduction and internal 


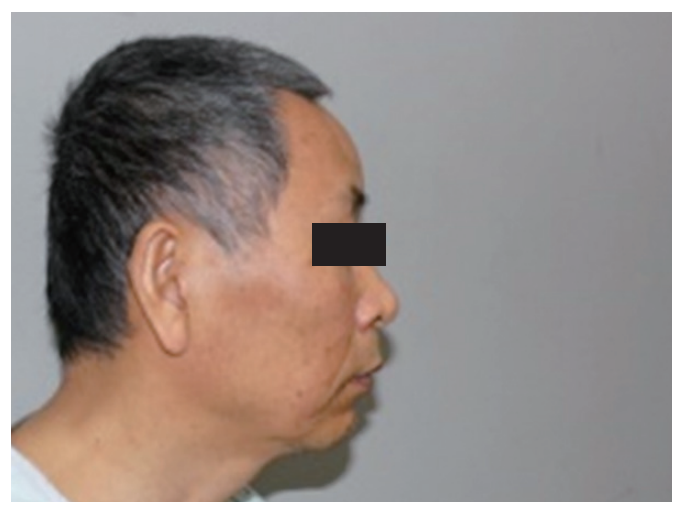

Fig. 2. In this patient with craniectomy and cranioplasty with Medpor, the right forehead has a conspicuous scar with depressed contour.

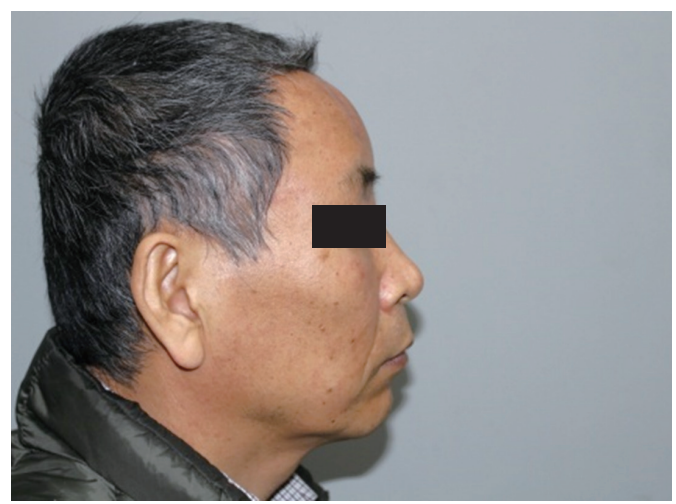

Fig. 3. Fat grafting was helpful for decreasing the visibility of the scar and contour irregularity.

fixation of the frontal sinus anterior wall, maintenance of sinus function preserving the continuity of nasofrontal duct drainage, and sinus obliteration (with a broad range of matters). Some complicated cases of frontal sinus fractures may require sinus cranialization; however, the benefit of cranialization was controversal [27]. Clinical and experimental evidence suggest that duct obstruction and/or remnant sinus mucosa due to inadequate obliteration are serious predisposing factors of infectious complications [28].

\section{Sinusitis}

Frontal sinusitis, with or without gross purulence, usually results from intermittent obstruction of the nasofrontal drainage system. After frontal sinus injury, the frontal sinus can drains through venules known as the foramina of Breschet into the dural veins, allowing for intracranial spread of pathogens. Debate surrounds the use of prophylactic antibiotics, especially beyond the perioperative period with a large meta-analysis failing to show a significant decrease in the risk of meningitis and any other infectious complication [29-30]. Such data must be weighted against the risk of severe opportunistic infections and selecting for resistant flora. Intractable frontal sinus infection can spread into the ethmoid sinus as well. Sinusitis with osteomyelitis should be addressed with adequate debridement, and the resulting dead space should be obliterated with a well-vascularized flap. The delay in necessary operation is one major risk factor for serious infection, and operations performed within 48 hours of injury is associated with the risk of severe infections [31]. Surgeons should not hesitate to operating on a patient with risk factors for infection, such as multiple fractures and CSF leakage.

The key to successful control of intractable infection is to seal the anterior skull base with sufficient volumes of a flap of wellvascularized tissue because vascularized tissue is believed to provide better protection against infection [32]. If the infection extends beyond the frontal sinus into the ethmoid sinus, both spaces should be obliterated. Adequate debridement of infected tissue is crucial to treat sinusitis. In these cases, local flaps may not be sufficient and require the use of a free muscular flap [32]. When the recipient vessel is injured or not available, reverse temporalis muscle flap could be a good alternative. Because this method provides a large arc of rotation and a relatively large volume of muscle, it could be also used for when severe soft tissue scarring make for a difficult galea or pericranial flap harvest [33].

\section{Mucocele and mucopyocele}

The most frequent complication from inadequate drainage of frontal sinus is mucocele. The frontal sinus mucosa can be tenacious, and inadequate drainage of mucus can manifest as a mucocele even though many years later [15]. A mucocele results from the regrowth of remnant mucosa and subsequent resumption of mucus production without a patent nasofrontal duct. Infected mucoceles are referred as mucopyocele or pyocele, which contains pus. Untreated frontal sinus fracture could made mucocele with the closure of the frontal sinus ostium by a block of bone after several years [34]. 
Clinically, symptoms of mucocele are benign in most cases [34]. Headache is the most common symptom, and other symptoms include proptosis, diplopia, nasal congestion, fluid leakage from the nose, and swelling over the forehead [35]. The anterior table is thick, whereas the posterior table is very thin. Therefore the mucoceles are expanded to posterior and inferior direction that made symptoms decribed above. In severe cases, strabismus may arise secondary to bilateral frontal sinus mucocele [36]. On CT images, a mucocele appears as a non-enhancing, low-attenuation expansile mass, and MRI studies show mucoceles as well-defined, expansile masses with variable signal intensities on $\mathrm{T} 1$ and $\mathrm{T} 2 \mathrm{imag}$ es [37].

Mucoceles that result from trauma are mostly due to compromised ventilation, and have been reported to occur between 1 and 35 years later in the literature [38]. Late appearance of mucoceles (or mucopyocele) remains always a possibility and, therefore, longterm clinical and computed tomography scanning follow-up have been suggested. Preventive cranialization of the frontal sinus to prevent secondary mucocele following frontal bone fracture is controversial [39].

Treatment of a mucocele consist of removing the mucocele sac and reestablishment of normal sinus drainage. Studies have reported success rates between $78 \%$ and $97 \%$ for external approaches, the Lynch and modified Lynch procedures, and osteoplastic flap techniques with or without frontal sinus obliteration [40]. The safest way to management a mucocele is to remove the sinus mucosa completely. Many surgeon perform a standard external approach combined with cranialization of the frontal sinus, meticulous eradication of the mucosa, and wide nasal drainage from the frontal base to the nasal cavity, and reconstructing the soft tissue and bony framework. Open approaches such as obliteration or cranialization have been shown to be effective in treating the problem, although recurrence rates have been reported to be as high as $25 \%$ [41]. In most cases, newly created extradural spaces become obliterated by the expansion of the frontal lobe within several weeks. In addition, vascularized local flaps, such as galeal frontalis, pericranial, or transverse glabellar, are highly effective in preventing contamination of the anterior cranial fossa from the paranasal space as vascularized option for sinus obliteration. The author prefers to use the galeal frontalis myofascial flap because of the following: (1) good vascular supply, (2) enough volume to fill the dead space of the frontal sinus, (3) narrow flap allows for greater degrees of rotation, (4) and short operation time [42]. This flap should be in the armamentarium of any surgeon faced with the task of sinus obliteration. However, when the mucocele is detected in an early stage, the treatment options of mucocele include minimally invasive approaches, which have considerably less morbidity.

\section{Osteomyelitis of frontal bone}

Osteomyelitis of frontal bone occurs because of severely comminuted, through-and-through frontal sinus fracture [43]. Chronic sinusitis could be a cause of osteomyelitis due to failed attempts at obliterating sinus mucosa and improper partitioning of the upper aerodigestive system from the anterior cranial base $[44,45]$. Since the introduction of antibiotics, frontal bone osteomyelitis has become a uncommon complication. When osteomyelitis is present, however, antibiotic treatment is rarely effective because of the lack of blood supply to the necrotic bone and bone sequestra. It is important for the surgeon to review prior interventions to fully appreciate the extent of debridement needed and the availability of reconstructive plans. Once osteomyelitis has set-in, radical debridement is crucial to removal all necrotic dead tissue, foreign bodies, and hypertrophic granulation tissue with high bacterial counts. After proper debridement, the reconstruction could be performed with alloplastic or autologous materials.

Although numerous studies have reported using non-vascularized materials for sinus obliteration, the author is of the opinion that non-vascularized material itself can serve as a nidus for infection $[44,45]$. It is generally accepted that well-vascularized tissues have greater ability to resist local soft-tissue infection and control osteomyelitis. Among various local flaps, the pedicled temporalis muscle myofascial flap has been demonstrated to be a useful and safe option in craniofacial reconstruction and for cranial base defects. The galea flap and pericranial flap is not recommended because these usually cannot provide sufficient volume [46]. The temporal muscle flap is most frequently used for laterally and antero-laterally located defects, although it can be mobilized across 
the midline [47]. Coverage of defect by local flaps have advantages of easier surgical technique, matching skin texture and thickness, shorter operation time, and less donor-site morbidity, when compared with free-tissue transfers. However, various free tissue transfer method have been described for reconstruction of forehead defects [47-52]. Microvascular free flaps are superior to local flaps in providing a good sealing of the anterior cranial base, adequate filling up the dead space with a viable muscle and taking care that no virtual cavity was left behind. Free flaps also provide the benefit of enhanced circulation to overcome local infections, promoting rapid wound healing and skin revascularization [53]. The choice of most appropriate reconstruction depends on the location and size of the defect, type of tissue needed, and preferences of the surgeon.

\section{Pott's puffy tumor}

Pott's puffy tumor (PPT), first described by Sir Percivall Pott in 1760 , is a rare clinical entity characterized by subperiosteal abscess associated with osteomyelitis. It is an osteomyelitis of the anterior wall of frontal bone commonly due to a frontal sinusitis (hematogenic spread) or, less commonly, due to frontal blunt trauma and frontal sinus reconstruction (direct translocation), of which the latter type of spread is limited to the adolescent age group [54-56].

The tumor results in a swelling on the forehead, hence the name. The infection can spread inwards, leading to an epidural abscess, cortical vein thrombosis, subdural empyema, and brain abscess. Treatment of PPT generally consists of surgical drainage and long-term antibiotics.

\section{Other infectious problem}

Among frontal sinus fracture patients, delayed complications such as meningitis and encephalocele are very rare but are potentially life threatening [57]. Such complications require a multidisciplinary team that includes plastic surgery, neurologic surgery, otolaryngology, infectious disease, and critical care.

\section{CONCLUSION}

The frontal sinus is located the upper one-third of the facial skele- ton. Frontal sinus fractures can result in a broad spectrum of complications, from forehead contour deformity to life-threatening infections. Therefore, each frontal sinus fracture patient should be informed to the possible complications and the importance of long-term follow up. Appropriate initial management is most important to minimize the risk of these complications.

Although contour deformity of forehead can be treated with various graft methods, fat grafting is a first line treatment because it is minimally invasive and simple. Autologous and alloplastic bone are indicated for moderate-to-severe bony displacement.

Almost every complications of frontal sinus fracture are related to infections. Extensive surgical debridement and adequate volume replacement are required to control these infections. The authors suggest surgeons to be familiar with various methods of treatment available in the prevention and management of complications following frontal sinus fractures, which is helpful in making the proper decision for secondary frontal sinus fracture surgery.

\section{REFERENCES}

1. Xie C, Mehendale N, Barrett D, Bui CJ, Metzinger SE. 30-year retrospective review of frontal sinus fractures: The Charity Hospital experience. J Craniomaxillofac Trauma 2000;6:7-15.

2. Rice DH. Management of frontal sinus fractures. Curr Opin Otolaryngol Head Neck Surg 2004;12:46-8.

3. Manolidis S, Hollier LH Jr. Management of frontal sinus fractures. Plast Reconstr Surg 2007;120(7 Suppl 2):32S-48S.

4. McRae M, Momeni R, Narayan D. Frontal sinus fractures: a review of trends, diagnosis, treatment, and outcomes at a level 1 trauma center in Connecticut. Conn Med 2008;72:133-8.

5. Carter KB Jr, Poetker DM, Rhee JS. Sinus preservation management for frontal sinus fractures in the endoscopic sinus surgery era: a systematic review. Craniomaxillofac Trauma Reconstr 2010;3:141-9.

6. Muminagic S, Masic T, Babajic E, Asotic M. Managment of frontal sinus fracture: obliteration sinus with cancellous bone graft. Med Arh 2011;65:250-1.

7. Gossman DG, Archer SM, Arosarena O. Management of frontal sinus fractures: a review of 96 cases. Laryngoscope 2006;116:1357-62.

8. Luce EA. Frontal sinus fractures: guidelines to management. Plast Reconstr Surg 1987;80:500-10.

9. Donald PJ, Bernstein L. Compound frontal sinus injuries with intracranial penetration. Laryngoscope 1978;88(2 Pt 1):225-32.

10. Chen KT, Chen CT, Mardini S, Tsay PK, Chen YR. Frontal sinus frac- 
tures: a treatment algorithm and assessment of outcomes based on 78 clinical cases. Plast Reconstr Surg 2006;118:457-68.

11. Hueman K, Eller R. Reduction of anterior frontal sinus fracture in volving the frontal outflow tract using balloon sinuplasty. Otolaryngol Head Neck Surg 2008;139:170-1.

12. Adkins WY, Cassone RD, Putney FJ. Solitary frontal sinus fracture. Laryngoscope 1979;89(7 Pt 1):1099-104.

13. Kalavrezos N. Current trends in the management of frontal sinus fractures. Injury 2004;35:340-6.

14. Nahum AM. The biomechanics of maxillofacial trauma. Clin Plast Surg 1975;2:59-64.

15. Wallis A, Donald PJ. Frontal sinus fractures: a review of 72 cases. Laryngoscope 1988;98(6 Pt 1):593-8.

16. Kim DW, Yoon ES, Lee BI, Dhong ES, Park SH. Fracture depth and delayed contour deformity in frontal sinus anterior wall fracture. J Craniofac Surg 2012;23:991-4.

17. Tieghi R, Consorti G, Clauser LC. Contouring of the forehead irregularities (washboard effect) with bone biomaterial. J Craniofac Surg 2012;23:932-4

18. Chen TM, Wang HJ, Chen SL, Lin FH. Reconstruction of post-traumatic frontal-bone depression using hydroxyapatite cement. Ann Plast Surg 2004;52:303-8.

19. Friedman CD, Costantino PD, Synderman CH, Chow LC, Takagi S. Reconstruction of the frontal sinus and frontofacial skeleton with hydroxyapatite cement. Arch Facial Plast Surg 2000;2:124-9.

20. Mathur KK, Tatum SA, Kellman RM. Carbonated apatite and hydroxyapatite in craniofacial reconstruction. Arch Facial Plast Surg 2003;5:379-83

21. Baker SB, Weinzweig J, Kirschner RE, Bartlett SP. Applications of a new carbonated calcium phosphate bone cement: early experience in pediatric and adult craniofacial reconstruction. Plast Reconstr Surg 2002;109:1789-96.

22. Verret DJ, Ducic Y, Oxford L, Smith J. Hydroxyapatite cement in craniofacial reconstruction. Otolaryngol Head Neck Surg 2005;133:8979.

23. Xie Y, Li Q, Zheng D, Lei H, Pu LL. Correction of hemifacial atrophy with autologous fat transplantation. Ann Plast Surg 2007;59:645-53.

24. Bourguet J, Bourdiniere J, Subileau C, Le Clech G. Otorhinolaryngology and ethmoido-frontal injuries. J Fr Otorhinolaryngol Audiophonol Chir Maxillofac 1977;26:95-105.

25. Le Clech G, Bourdiniere J, Rivron A, Demoulin PY, Inigues JP, Marechal V. Post-traumatic infections of the frontal sinus. Rev Laryngol Otol Rhinol (Bord) 1990;111:103-5.

26. Metzinger SE, Metzinger RC. Complications of frontal sinus fractures. Craniomaxillofac Trauma Reconstr 2009;2:27-34.

27. Weber R, Draf W, Kratzsch B, Hosemann W, Schaefer SD. Modern concepts of frontal sinus surgery. Laryngoscope 2001;111:137-46.

28. Donald PJ, Ettin M. The safety of frontal sinus fat obliteration when sinus walls are missing. Laryngoscope 1986;96:190-3.

29. Castro B, Walcott BP, Redjal N, Coumans JV, Nahed BV. Cerebrospinal fluid fistula prevention and treatment following frontal sinus frac- tures: a review of initial management and outcomes. Neurosurg Focus 2012;32:E1.

30. Ratilal BO, Costa J, Sampaio C, Pappamikail L. Antibiotic prophylaxis for preventing meningitis in patients with basilar skull fractures. Cochrane Database Syst Rev 2011;(8):CD004884.

31. Bellamy JL, Molendijk J, Reddy SK, Flores JM, Mundinger GS, Manson PN, et al. Severe infectious complications following frontal sinus fracture: the impact of operative delay and perioperative antibiotic use. Plast Reconstr Surg 2013;132:154-62.

32. Lin YT, Chen CT, Lai JP. Post-traumatic fronto-ethmoid osteomyelitis treated with free muscle transfer. J Plast Reconstr Aesthet Surg 2010;63:963-9.

33. Kim YO, Park BY. Reverse temporalis muscle flap: treatment of large anterior cranial base defect with direct intracranial-nasopharyngeal communication. Plast Reconstr Surg 1995;96:576-84.

34. Karli R. Closure of the frontal sinus ostium by a block of bone: unexpected cause of frontal mucocele. J Craniofac Surg 2013;24:e155-7.

35. Constantinidis J, Steinhart H, Schwerdtfeger K, Zenk J, Iro H. Therapy of invasive mucoceles of the frontal sinus. Rhinology 2001;39:33-8.

36. Koktekir BE, Karalezli A, Topal O, Erbek S. Strabismus secondary to frontal sinus mucocele associated with nasal polyposis. J Craniofac Surg 2012;23:e340-1.

37. Weber R, Draf W, Keerl R, Kahle G, Schinzel S, Thomann S, et al. Osteoplastic frontal sinus surgery with fat obliteration: technique and long-term results using magnetic resonance imaging in 82 operations. Laryngoscope 2000;110:1037-44.

38. Koudstaal MJ, van der Wal KG, Bijvoet HW, Vincent AJ, Poublon RM. Post-trauma mucocele formation in the frontal sinus; a rationale of follow-up. Int J Oral Maxillofac Surg 2004;33:751-4.

39. Horowitz G, Amit M, Ben-Ari O, Gil Z, Abergel A, Margalit N, et al. Cranialization of the frontal sinus for secondary mucocele prevention following open surgery for benign frontal lesions. PLoS One 2013;8:e83820.

40. Ulualp SO, Carlson TK, Toohill RJ. Osteoplastic flap versus modified endoscopic Lothrop procedure in patients with frontal sinus disease. Am J Rhinol 2000;14:21-6.

41. Al-Qudah M, Graham SM. Modified osteoplastic flap approach for frontal sinus disease. Ann Otol Rhinol Laryngol 2012;121:192-6.

42. Kim YJ, Kim HR, Jun YJ, Seo BC. Usefulness of vascularized galeal frontalis myofascial flap as treatment for postoperative infection in frontal sinus fracture. J Craniofac Surg 2011;22:1968-71.

43. Hardy JM, Montgomery WW. Osteoplastic frontal sinusotomy: an analysis of 250 operations. Ann Otol Rhinol Laryngol 1976;85(4 Pt 1):523-32.

44. Rohrich RJ, Hollier LH. Management of frontal sinus fractures: changing concepts. Clin Plast Surg 1992;19:219-32.

45. Weitzel EK, Hollier LH, Calzada G, Manolidis S. Single stage management of complex fronto-orbital mucoceles. J Craniofac Surg 2002;13:739-45.

46. Kim YH, Youn SK, Kim JT, Kim SW, Yi HJ, Kim CY. Treatment of the severely infected frontal sinus with latissimus dorsi myocutaneous 
free flaps. J Craniofac Surg 2011;22:962-6.

47. Jung SH, Aniceto GS, Rodriguez IZ, Diaz RG, Recuero II. Posttraumatic frontal bone osteomyelitis. Craniomaxillofac Trauma Reconstr 2009;2:61-6.

48. Weber SM, Kim JH, Wax MK. Role of free tissue transfer in skull base reconstruction. Otolaryngol Head Neck Surg 2007;136:914-9.

49. Yamada A, Harii K, Ueda K, Asato H. Free rectus abdominis muscle reconstruction of the anterior skull base. Br J Plast Surg 1992;45:302-6.

50. Lutz BS, Wei FC, Chen HC, Lin CH, Wei CY. Reconstruction of scalp defects with free flaps in 30 cases. Br J Plast Surg 1998;51:186-90.

51. West CA, Towns G, Bachelor AG, Liddington MI. Reconstruction of skull base and dura using rectus abdominis muscle combined with a vascularised fascial perforator flap. J Plast Reconstr Aesthet Surg 2006;59:631-5.

52. Disa JJ, Pusic AL, Hidalgo DH, Cordeiro PG. Simplifying microvas- cular head and neck reconstruction: a rational approach to donor site selection. Ann Plast Surg 2001;47:385-9.

53. Kim YH, Youn S, Sung IH, Kim JT, Hwang KT. Latissimus dorsi flap coverage of soft tissue defect following below-knee amputation: emphasis on flap design and recipient vessels. Eur J Orthop Surg Traumatol 2013;23:603-10.

54. Fokkens W, Lund V, Mullol J; European Position Paper on Rhinosinusitis and Nasal Polyps group. Complications of rhinosinusitis and nasal polyps. Rhinology 2007;45(Suppl 20):80-3.

55. Tattersall R, Tattersall R. Pott's puffy tumour. Lancet 2002;359:1060-3.

56. Banooni P, Rickman LS, Ward DM. Pott puffy tumor associated with intranasal methamphetamine. JAMA 2000;283:1293.

57. Gerbino G, Roccia F, Benech A, Caldarelli C. Analysis of 158 frontal sinus fractures: current surgical management and complications. J Craniomaxillofac Surg 2000;28:133-9. 